\title{
A epidemia transexual: histeria na era da ciência e da globalização?
}

\author{
Marco Antonio Coutinho Jorge*1
}

Natália Pereira Travassos*2

\begin{abstract}
Este artigo explora questões relativas à transexualidade partindo da noção psicanalítica da histeria como estrutura básica do sujeito. As impressionantes epidemias de histeria ocorridas ao longo da história revelam como a histeria produz questionamentos radicais sobre o enigma da diferença sexual dirigidos ao saber dominante de cada época. Para responder à questão sobre qual é o lugar da histeria na contemporaneidade, lançamos a seguinte hipótese: a mais significativa forma assumida pela histeria hoje é a epidemia de transexualidade, produzida no encontro com o discurso da ciência, dominante na cultura globalizada.
\end{abstract}

Palavras-chave: Psicanálise, histeria, transexualidade, epidemia

\footnotetext{
*1 Universidade do Estado do Rio de Janeiro - UERJ (Rio de Janeiro, RJ, Br.).

*2 ONG Grupo Arco-Íris de Cidadania LGBT. (Rio de Janeiro, RJ, Br.).
} 
É impressionante a crescente incidência das manifestações ligadas à transexualidade nas últimas décadas e hoje se espraiam em toda a cultura, do consultório de psicologia à novela de televisão. Um raro quadro psiquiátrico tem agora presença espetacular na mídia. Ao pesquisarmos numa plataforma de busca "transgêneros famosos" surge em primeiro lugar: "10 transgêneros famosos", que lista homens e mulheres trans ${ }^{1}$ que estão sempre presentes na mídia. O cabeçalho afirma: "Nascer com determinado sexo e não se identificar com ele é o drama de muita gente".

Essa frase generalizante, que não poderia ser ouvida há algumas décadas sem produzir mal-estar na maioria das pessoas, hoje pode ser dita sem causar maior espanto. $\mathrm{O}$ que ocorreu para que, atualmente, nascer com a alma feminina num corpo masculino (e vice-versa) seja reconhecido em todo o mundo como uma condição que deve receber da medicina total apoio e incentivo visando a mudança da anatomia corporal?

Este artigo explora, por meio da psicanálise, essas e outras questões. ${ }^{3}$ Abordaremos alguns elementos da transexualidade e suas manifestações, assim como examinaremos a estrutura do sujeito tal como concebida pela psicanálise, mediante os aportes trazidos por Jacques Lacan à obra de Sigmund Freud. A histeria ocupa aqui um lugar privilegiado e veremos, pelo histórico de suas epidemias registradas ao longo dos séculos, o quanto a histeria - a estrutura básica do sujeito - tem o poder de produzir questionamentos radicais sobre o enigma da diferença sexual. Muitos pesquisadores, dentre eles Sônia Leite (2016) e Denise Maurano (2010), já indagaram qual é o lugar da histeria na contemporaneidade. Nossa hipótese é de que ela se manifesta, entre outras formas, principalmente por meio dos fenômenos ligados ao gênero. A atual frequência

\footnotetext{
${ }^{1}$ Os sintagmas "homem trans" e "mulher trans" designam respectivamente mulheres e homens que mudaram o gênero.

${ }^{2}$ Recuperado em 14 de maio de 2017 de https://www.mensagenscomamor.com/ 10-transgeneros-famosos.

${ }^{3}$ Este artigo é parte do livro homônimo que está sendo finalizado pelos autores e será publicado ao final de 2017.
} 


\section{ARTIGOS}

epidêmica dos casos de transexualidade nos permite supor que ela pode ser a mais importante forma hodierna de histeria, produzida no encontro com as ciências médicas que, por sua vez, reduzem e banalizam os conflitos do sujeito com seu sexo, incitando-o a buscar o chamado processo transexualizador.

\section{A transexualidade na medicina e na psicanálise}

Sabemos que a ideia de transição de um sexo ao outro já surgira pontualmente na mitologia grega, pela voluptuosa estória de Tirésias que, ao ser punido pelos deuses, viveu parte da vida como mulher, o que lhe possibilitou experimentar dois campos de gozo e revelar que a mulher goza mais do que o homem. Contudo, o transexualismo, como desconforto entre o sexo anatômico e o desejo de adequação ao gênero através da transformação do corpo, só pode ser entendido a partir do momento em que a medicina proporcionou, através de seus avanços, intervenções que visavam atender a demanda transexual de estabelecer a correspondência entre sexo e gênero. Os primeiros médicos a se interessarem pela exploração das patologias sexuais ligadas ao que hoje podemos chamar de questões de gênero foram Magnus Hirschfeld e Henry Havelock Ellis, sendo que a literatura indica que Hirschfeld foi o primeiro a utilizar o sintagma transexualismo psíquico (seelischer Transsexualismus). Juntos, descreveram os quadros clínicos de travestismo e eonismo, respectivamente.

Alguns registros indicam que a primeira descrição de um caso que pode ser entendido como transexualismo foi feita pelo alienista francês JeanÉtienne Esquirol em 1838, classificado como démonomanie. Foi o médico generalista David O. Cauldwell que cunhou, em 1949, o sintagma psychophatia transexualis, num artigo homônimo publicado na revista Sexology, definindo como o mais incomum dos desvios sexuais o desejo mórbido patológico de ser um indivíduo completo do sexo oposto: "Esse desejo é tão forte que o indivíduo insiste em - mesmo sendo impossível - submeter-se à cirurgia que o transformaria numa mulher completa, ou ela num homem perfeito", esclarece o editor da revista (p. 274).

Em 1953, um ano após a intervenção cirúrgica realizada em George Jorgensen ${ }^{4}$ considerado caso princeps de cirurgia de transgenitalização,

\footnotetext{
${ }^{4}$ Um jovem americano de origem dinamarquesa que passou a adotar o nome de Christine Jorgensen após o procedimento cirúrgico.
}

Rev. Latinoam. Psicopat. Fund., São Paulo, 20(2), 307-330, jun. 2017 
o endocrinologista norte-americano Harry Benjamin definiu o transexual, homem ou mulher, como um indivíduo biologicamente normal (sem genitália ambígua), porém profundamente infeliz com seu sexo. Para Benjamin, os verdadeiros transexuais seriam aqueles que, diferentemente dos travestis, sentem-se pertencentes ao sexo oposto, não bastando-lhes a mudança da aparência sexual conferida pelas vestimentas. Assim, segundo ele, o principal fator para estabelecer a diferença entre travestismo e transexualismo seria o desejo de, através de cirurgias, fazer a adequação do corpo, incluindo a genitália:

O transexual, entretanto, coloca toda sua crença e futuro nas mãos do médico, particularmente do cirurgião. Esses pacientes querem passar pela cirurgia de correção, então chamada "operação de conversão", para que assim o corpo possa assemelhar-se àqueles do sexo ao qual sentem pertencer e desejam pertencer ardentemente. O desejo de mudar de sexo tem sido conhecido por psicólogos há muito tempo. Esses pacientes eram raros. Sua anormalidade tem sido descrita por jornais científicos no passado de várias formas; por exemplo, como "inversão sexual total" ou "inversão do papel sexual". Além de algumas tentativas com psicoterapia num (fracassado) esforço de curá-los de seus estranhos desejos, medicamente nada foi ou pôde ter sido feito por eles. Provavelmente muitos foram parar em instituições mentais, alguns na prisão, e a maioria como miseráveis, membros infelizes da comunidade, a não ser que cometam suicídio. O cenário mudou apenas por causa dos grandes avanços na endocrinologia e técnicas cirúrgicas. (Benjamin, 1966, p. 11; grifos nossos)

Assim, a ratificação da demanda do transexual pelo discurso médico surge desde o início como uma necessidade imprescindível.

A repercussão do caso de Christine Jorgensen provocou um aumento significativo do número de pessoas que buscaram na cirurgia e na terapia hormonal a possibilidade de resolver o conflito causado pelo sentimento de ter um corpo em desarmonia com a própria imagem, algo que nem sempre se refere especificamente à genitália, mas inevitavelmente coloca a identidade sexual em questão.

Lia Amorim e Marco Antonio Coutinho Jorge (1982) apontaram a dificuldade da psiquiatria em lidar com o transexualismo, relacionando a construção dessa categoria nosográfica com influências morais e ideológicas que requerem uma avaliação minuciosa. A absoluta uniformidade da descrição do quadro clínico por diferentes autores chama atenção quanto à falta de espaço para qualquer dúvida ou interrogação em relação à diferença sexual, como se o saber científico não suportasse a emergência do não saber. Assim, não é possível deixar de salientar que a cristalização imaginária inerente à certeza 


\section{ARTIGOS}

do transexual sobre sua pertença ao sexo oposto é imediatamente acompanhada pela proposição curativa do saber médico. É, de fato, bastante surpreendente que surja aqui a oferta feita com absoluta falta de questionamento pelo discurso médico, que oferece como numa linha de montagem a escolha do gênero e suas insígnias tal qual uma esteira de produção industrial, sendo o objeto de consumo o corpo. Como considerou Jean-Pierre Lebrun, "esta é uma medicina de pura e simples resposta à demanda" (p. 67).

Marcel Czermak (1986/1991) sublinhou que o transexualismo escancara a absoluta ausência de naturalidade da relação do sujeito com seu próprio corpo e exibe o caráter heterogêneo do falo em relação ao pênis e a frequente superposição imaginária dos dois. A ideia da necessidade de corrigir um "erro da natureza" traz implícita uma certeza sobre algo que, ao contrário, está marcado por uma hiância estrutural: o corpo (o eu corporal) e o sujeito. Paradoxo que se evidencia na própria maneira ambígua pela qual o discurso médico trata da questão: embora o transexualismo esteja alojado no rol das síndromes psiquiátricas, sua "cura" tem sido proposta exclusivamente pela via da manipulação do corpo, ressalta Paola Mieli (2002). Se a psicanálise sustenta o tratamento do real pela via do simbólico, ${ }^{5}$ tal certeza do sujeito sobre o sexo inverte essa perspectiva levando-o a demandar a correção corporal: a exigência transexual reduz-se à harmonia entre corpo e sujeito. Tal certeza, salientada por Lacan como uma característica comum da estrutura psicótica, levou muitos psicanalistas a considerarem a transexualidade como uma manifestação da psicose. Moustapha Safouan (1979b), um de seus discípulos mais eminentes, formularia nessa direção: "A única certeza aberta ao pensamento do homem quanto ao seu sexo é a certeza schreberiana de ser uma mulher" (p. 118).

Introduzindo uma leitura não patologizante sobre as perversões e o transexualismo, Robert Stoller foi, de fato, o primeiro psicanalista a se dedicar aos estudos de gênero, tornando-se o maior especialista americano sobre o assunto. A maioria dos analistas que se debruçou sobre o tema retomou sua obra, dentre eles Jacques Lacan e seus alunos Moustapha Safouan, Marcel Czermak, Catherine Millot e Geneviève Morel.

Sex and Gender (1968), primeiro livro de Stoller sobre o assunto, surgiu como resultado de dez anos da pesquisa que incluiu a escuta de

\footnotetext{
${ }^{5}$ Podemos encontrar essa ideia já no texto de Freud (1905/1972c), "O tratamento psíquico (ou mental)".
}

Rev. Latinoam. Psicopat. Fund., São Paulo, 20(2), 307-330, jun. 2017 
pacientes e familiares, trazendo uma visão inovadora sobre a identidade de gênero. Em A experiência transexual (1975/1982), definiu o transexualismo como uma desordem "na qual uma pessoa anatomicamente normal sente-se como membro do sexo oposto e, consequentemente, deseja trocar seu sexo, embora suficientemente consciente de seu verdadeiro sexo biológico" (p. 2). Preocupado já naquela época com o crescente número de casos, Stoller apontou a influência da publicidade e a disseminação do assunto na sociedade como fatores complicadores para o diagnóstico. $\mathrm{O}$ autodiagnóstico ${ }^{6}$ e a prescrição terapêutica formulada pelos próprios pacientes poderiam, em alguns casos, ocultar um delírio bem estruturado de uma psicose, e, em outros, isentar sujeitos homossexuais de ter que lidar com a própria sexualidade em tempos de grande repressão à homossexualidade.

A importante crítica que Stoller recebeu de Lacan dizia respeito à inconsistência teórica com a qual construiu sua argumentação, destacando que o conceito de foraclusão por ele introduzido seria crucial para situar os casos trabalhados no campo da psicose. Na década de 1980, o interesse da psicanálise pelo transexualismo ainda era pequeno. Depois de Stoller, muitos psicanalistas que escreveram sobre o tema já estavam influenciados pela leitura 312 lacaniana de Freud e trouxeram diversas contribuições para pensar a clínica da transexualidade.

Lacan retificou a hipótese de Freud sobre a homossexualidade na base da paranoia, deslocando-a para o transexualismo como manifestação sintomática. A partir daí, a referência às memórias do presidente Schreber tornou-se frequente na abordagem do assunto. Apesar de Schreber estar inequivocamente situado no campo da psicose, não se pode restringir essa estrutura à presença ou ausência do delírio - uma crença errônea de Stoller que foi duramente criticada pelos clínicos subsequentes a ele.

Moustapha Safouan foi o primeiro a situar no centro da discussão a posição do desejo, permitindo retomar o tema do transexualismo à luz da psicanálise. Apoiado na teoria lacaniana, ressaltou a importância de considerar a inscrição do significante do Nome-do-Pai (Lacan, 1959/1966) ${ }^{7}$ para a assunção de uma posição subjetiva em relação ao desejo do Outro e a seu próprio sexo.

${ }^{6}$ J.P. Lebrun (1999) salienta que o autodiagnóstico é o fator responsável pela impossibilidade de se saber o que é um "verdadeiro" transexual.

${ }^{7}$ O Nome-do-Pai é "o significante que, no Outro como lugar do significante, é o significante do Outro como lugar da lei” (p. 590). 


\begin{abstract}
ARTIGOS
Os trabalhos iniciais de Czermak sobre o transexualismo, contemporâneos ao de Safouan, apoiam-se na discussão estruturalista lacaniana, mas se estendem mais além - assim como os de Millot e Morel - e alcançam momentos mais avançados da teoria de Lacan, que incluem: primeiro, o posicionamento do sujeito diante da partilha sexual - marcado por dois campos distintos de gozo; e segundo, a nodulação borromeana, que permite repertoriar o transexualismo como sinthoma, que amarra os registros real (R), simbólico (S) e imaginário (I). Nessa perspectiva, segundo Czermak (1991), o transexual quer se transformar n'A Mulher que não existe, dotada de beleza, unidade, aquela que agrega tudo em um: um dos Nomes-do-Pai cujo delírio se traduz no "colapso do corpo na vestimenta, em um autêntico delírio de envoltório" (p. 95).
\end{abstract}

\title{
O enigma da histeria
}

Possuindo uma história que atravessa as épocas, a histeria nos leva a indagar o que significa essa patologia polimorfa que assume as mais variadas aparências em diferentes períodos. ${ }^{8}$ Como afirmou Sydenham (apud Briquet, 1859), "as formas de Proteus 9 e as cores do camaleão não são mais numerosas do que os diversos aspectos sob os quais a histeria se apresenta" (p. 5). O caráter "migratório" de sua sintomatologia foi indicado desde os primeiros estudos da medicina antiga e seu nome próprio tem o instrutivo mérito de estar associado ao útero - hysteros, em grego - logo, à sexualidade

\footnotetext{
${ }^{8}$ Muitos trabalhos foram dedicados a retraçar essa história: História da histeria, de Etienne Trillat; Histoire de l'hystérie, de Ilza Veith; Historia de la histeria, de Diane Chauvelot; Historia universal de la histeria, de Malele Penchansky; Invention de l'hystérie, de Georges DidiHuberman, entre outros.

${ }^{9}$ Proteus era um deus marinho, um dos três mil filhos dos titãs Tétis e Oceano. Nascido em Palene, uma pequena cidade da Macedônia, ele teve dois filhos gigantes e cruéis: Tmolos e Telégono. Não conseguindo transmitir o sentimento de humanidade para seus filhos, Proteus pediu ajuda a Netuno. O deus do mar aconselhou Proteus a abandonar sua cidade e ir com ele cuidar do grande rebanho de peixes e focas nas costas do Egito. Depois de algum tempo, Netuno quis recompensá-lo por seu trabalho e concedeu-lhe o conhecimento do presente, do passado e do futuro. Proteus passou a ser reverenciado por seus dons proféticos e reveladores do destino. Muitas pessoas passaram a procurá-lo desejando conhecer as artimanhas do destino, porém Proteus se mostrava arredio para revelar os acontecimentos vindouros. Ele considerava que cada um poderia fazer seu próprio destino por meio de suas ações. Para se esquivar das pessoas, Proteus se metamorfoseava assumindo aparências monstruosas fazendo as pessoas fugirem assustadas.
} 
feminina. Falava-se na época de Hipócrates e depois Galeno do útero "passeador", responsável pela plasticidade sintomática.

Além disso, o paciente histérico tem o poder de mimetizar - utilizase muitas vezes o termo simular, mas a noção de simulação corre o risco de considerar erroneamente o histérico um sujeito consciente de suas ações - os mais diversos quadros clínicos. Após aprenderem muito cedo a estabelecer o diagnóstico diferencial entre a crise epilética e o ataque histérico, os psiquiatras se dão conta de que, ao se dirigirem à enfermaria do hospital para atender algum paciente internado, serão também mobilizados para atender pacientes histéricos que, ao verem-no consultando, desencadeiam crises diversas para receber cuidados semelhantes. Outra característica marcante da histeria, sua sensibilidade ao contágio, foi relacionada por Freud à identificação histérica. Ele menciona o episódio de uma jovem num internato que, tendo desencadeado uma crise histérica após receber uma carta, foi seguida por outras jovens que com ela se identificaram no sofrimento amoroso.

Dois grandes marcos balizam o trajeto da histeria na medicina: o Traité clinique et thérapeutique de l'hystérie, de Paul Briquet, publicado em 1859, primeiro tratado médico que empreendeu um estudo objetivo e sistemático 314 sobre o assunto; ${ }^{10}$ e os experimentos de hipnose realizados por Jean-Martin Charcot com as pacientes histéricas na Salpêtrière, a partir dos anos 1870, que representaram o reconhecimento de seu estatuto de entidade clínica. Com o primeiro, a histeria ganha direito à ciência: Briquet e sua equipe estudaram nada menos que 430 pacientes histéricas durante dez anos. Quanto a Charcot, ele entrou na história como neurologista e ainda que tenha sido o responsável pelo redescobrimento da histeria, quando faleceu não mais era conhecido por sua prática com pacientes histéricas, que forneceu a Freud os elementos para construir o edifício teórico da psicanálise.

Considerada mentirosa e teatral, a histérica foi rechaçada pela medicina. Como seus sintomas nada significam para o discurso médico, ela sempre recebeu do médico a resposta: "— Você não tem nada." Se suas crises foram agraciadas com o termo "piti"11 (cf. Postel, 2011, p. 350), isso se deu porque tendo seus sintomas sido considerados simulação, ela foi desqualificada

\footnotetext{
${ }^{10} \mathrm{O}$ tratado de Briquet foi amplamente conhecido e citado em sua época, mas caiu no ostracismo com o advento do conceito psicanalítico de histeria ao final do século XIX.

${ }^{11}$ Abreviatura de pitiatismo, denominação introduzida por J. Babinsky para criticar os trabalhos de Charcot sobre a histeria e questioná-la como verdadeira entidade mórbida. Para ele, toda a patologia histérica é simulada e trata-se apenas de "patomimia".
} 


\section{ARTIGOS}

como doente. Ela não desempenha bem esse papel, pois seus sintomas não cessam mesmo após terem sido esgotados todos os recursos mais modernos da medicina.

Mas o trabalho desenvolvido por Charcot no período em que Freud se dirigiu à Salpêtrière para realizar seu estágio de alguns meses, inaugurou uma nova era de compreensão da histeria que levaria à criação da psicanálise. Charcot estabeleceu as bases pelas quais Freud iria reorganizar o saber sobre a histeria em moldes inéditos. A sugestionabilidade histérica evidenciada por ele nos experimentos de hipnose - na sequência do magnetismo animal de Mesmer, o verdadeiro precursor da clínica da histeria -, abriu para Freud as portas da transferência, creodo (caminho obrigatório) de acesso ao inconsciente. ${ }^{12} \mathrm{~A}$ fantasia inconsciente, com a qual Freud se deparou após abandonar a teoria da sedução e do trauma sexual, revelou-lhe que na etiologia das neuroses não se tratava mais do trauma sexual, mas sim do sexo como traumático. ${ }^{13}$ Em termos lacanianos, Freud abandonou a causalidade de um real externo ao sujeito e introduziu a dimensão de outro real — interno - , representado pela própria pulsão, com seu objeto inespecífico.

A histeria atravessou os séculos transmutando sua aparência sempre referenciada ao discurso dominante: demoníaca e feiticeira na Idade Média; doente mental, no nascimento da psiquiatria, de uma patologia cuja plasticidade fez com que Freud, que chegou a considerar a histeria la bête noire da medicina, dissesse a Jung que ela "é $a$ enfermidade em comparação com a qual todas as outras enfermidades nervosas são apenas raridades" (Maleval, 2009, p. 63). O psiquiatra Étienne Trillat (1991) chamou-a de "objeto extravagante", "objeto não identificado", "terra incógnita" que utiliza o corpo para manifestar sua presença.

Alguns eventos marcam essa dupla inscrição da histeria ao longo do tempo, que ilustra à perfeição a passagem da idade das sombras à era da ciência. Essa história narra como os histéricos sofreram a influência dos discursos dominantes através das diferentes épocas. Considerada bruxa e herege pela Igreja, a histérica foi queimada viva nas fogueiras da Inquisição,

${ }^{12}$ Como formulou Lacan (1964/1979), "a transferência é a atualização da realidade do inconsciente" (p. 142).

${ }^{13}$ Encontramos essa noção no texto de Freud (1906[1905]/1972b), "Meus pontos de vista sobre o papel desempenhado pela sexualidade na etiologia das neuroses". Vide igualmente a noção lacaniana do trauma como contingência em Lacan (1960/1998c), "Subversão do sujeito e dialética do desejo no inconsciente freudiano". 
para mais tarde encontrar um lugar nos compêndios de psiquiatria. Tudo se passa como se a histérica se deslocasse, através dos anos, sempre antenada e referida ao discurso dominante de sua época. Esse deslocamento evidencia a posição que a histérica adota em relação ao saber do mestre: ela está sempre próxima dele, o segue de perto e, se o faz, é na medida em que insiste em colocar uma pergunta crucial que a move: sou homem ou mulher?

A questão da histeria é a mesma do transexual que pede uma resposta hormonio-cirúrgica ao saber tecno-científico dominante. Tal como a carta roubada do conto de Edgar Allan Poe, que para ser ocultada é colocada à vista de todos, tudo indica que uma epidemia trans está diante de nossos olhos: sob a forma da transexualidade, a histeria parece prosseguir hoje colocando suas perguntas sobre os enigmas do sexo. O elevado número de casos de transexualidade tem tudo para ser considerado uma nova epidemia de histeria, talvez mesmo uma pandemia de histeria - uma epidemia na era da globalização.

\section{Histeria e estrutura}

Todo sujeito falante, porque falante, é histérico: esse é o mistério da histeria, talvez incompreensível fora do campo da psicanálise - a histeria é a estrutura discursiva de base do sujeito falante, esclarece José Monseny (1998). Lacan escreveu o matema do discurso da histérica (do histérico) ${ }^{14}$ para situar nele a estrutura discursiva em que o sujeito, produzido originariamente pelo discurso do mestre - no qual ele é alienado nos significantes do Outro ${ }^{15}$-, interroga o saber sobre a diferença sexual. A binaridade significante $\left(\mathrm{S}_{1}-\mathrm{S}_{2}\right)$, que reparte o campo do sexual em dois sexos absolutamente distintos homem e mulher - é interrogada pelo histérico a partir daquilo que é impossível de ser apreendido pelo significante - o objeto $a$.

Assim, na posição de agente do discurso, o sujeito surge dividido como efeito da linguagem no conflito sintomático, mas sua verdade é que ele se coloca como objeto do desejo, o objeto $a$, indecifrável para o Outro. E todo saber que o mestre $\left(\mathrm{S}_{1}\right)$ produzir $\left(\mathrm{S}_{2}\right)$ será impotente para dar conta do enigma da sexualidade $(a)$. Tendo certa vez feito um lapso no seminário e se

${ }^{14}$ Para uma introdução à teoria dos quatro discursos em Lacan consultar: Jorge, M.A.C. (2002), "Discurso e liame social: apontamentos sobre a teoria lacaniana dos quatro discursos".

${ }^{15} \mathrm{O}$ Outro é o lugar dos significantes. 


\section{ARTIGOS}

autodesignado no feminino, Lacan se disse um histérico analisado que ainda tinha, contudo, alguns resíduos sintomáticos.

\begin{tabular}{|c|c|c|c|c|}
\hline Lugares: & & Mestre: & & stér \\
\hline agente $\rightarrow$ & outro & $S_{1} \rightarrow S_{2}$ & $\$$ & $\rightarrow$ \\
\hline verdade & produto & $\$ \quad / / a$ & $a$ & /I \\
\hline
\end{tabular}

A histeria significa uma interrogação sobre o real do sexo, ou seja, sobre o enigmático objeto faltoso da pulsão que, assim como formulou Freud, não é específico, mas ao contrário é inteiramente variável e inapreensível: todo e qualquer objeto pode ocupar o lugar do objeto da pulsão, daí a diversidade da sexualidade humana, diferente do funcionamento instintivo dos animais. Todo saber que se propõe a abarcar esse real do sexo - o impossível de ser representado pelo simbólico, pela linguagem —, será questionado pela histérica. Por isso, ela se dirige ao mestre - o mestre da contingência, seja ela qual for: religião, ciência, psicologia, sexologia ou psicanálise — para demandar um saber sobre o sexo e, em seguida, destituí-lo de sua potência. Pois o que ela sustenta é que não há saber possível sobre a diferença sexual - evasiva a todo e qualquer saber. Diferentes disciplinas científicas visam produzir saber sobre a sexualidade, mas o único que derrogou a histeria de sua presunção combativa do saber do mestre foi o saber freudiano construído em torno da bissexualidade estrutural, que inclui nela mesma o real pulsional (objeto $a$ ) inapreensível pela linguagem.

As figuras clínicas da histeria correspondem a essa indagação sobre o sexo que ela encarna com seus sintomas: a figura da outra mulher, ou do outro homem, que traz embutida nela a dor sobre "o que ela (ele) tem que eu não tenho?"; a manutenção da insatisfação, que preserva o desejo da histérica; a identificação com o desejo do Outro que visa interrogá-lo. Essa evasividade do quadro histérico ao saber médico se explica quando se entende que os sintomas histéricos não remetem ao discurso médico, como signos (ou sinais) médicos, mas ao próprio sujeito, como significantes que o representam. ${ }^{16}$

${ }^{16}$ A diferença entre o signo e o significante, estabelecida por Lacan em sua reconstrução do saber freudiano apoiado na linguística, permite localizar duas diferentes formas de sintoma passíveis de serem repertoriadas - ou não - pela medicina. Cf. Jorge, M.A.C. (2000) Fundamentos da psicanálise de Freud a Lacan - vol. 1: as bases conceituais; Clavreul, J. (1983), A ordem médica. 


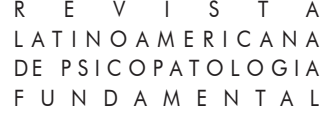

Como revelou Freud, não há inscrição da diferença sexual no inconsciente. Assim, no campo do simbólico no qual o sujeito é representado e do qual ele é efeito, a diferença sexual não encontra uma distinção certeira como aquela exposta na imagem da genitália ou no real do corpo pelas ciências da anatomia, endocrinologia, embriologia e genética. Desde os primeiros relatos sobre o desacordo entre o corpo e a identidade sexual, a medicina busca solução para corrigir o "erro da natureza" de que sofre o transexual, sobretudo pelo aprimoramento das técnicas cirúrgicas e da terapia hormonal. A gravidade está no fato de a ciência acabar criando - e até promovendo - a demanda de transformação corporal para o sujeito histérico que não encontrará apaziguamento de seu conflito através dela. A frequência igualmente crescente de casos de sujeitos que buscam a destransição após terem mudado de gênero fala a favor da perene insatisfação que condiciona o desejo na histeria.

A certeza transexual de pertencer ao sexo oposto a seu sexo biológico é uma tentativa de dar uma resposta consistente à questão "qual o meu sexo: homem ou mulher?", que remonta aos primórdios da psicanálise. Da questão da paciente Dora sobre o seu sexo até o questionamento feito por Freud a Marie Bonaparte sobre "O que quer a mulher?", a resposta ao enigma da diferença sexual possui estrutura de ficção: toda resposta cabe, mas nenhuma consiste na verdade absoluta.

Novas formas de histeria se apresentam hoje, mas talvez a mais frequente delas seja a transexualidade que invadiu a clínica médica, afirmando a disparidade entre anatomia e subjetividade, forma última de interrogar o saber sobre o sexo: o que é o homem, o que é a mulher? Se no início se concebeu a transexualidade como uma forma sintomática da psicose, hoje fica claro que nem toda transexualidade é psicótica. Ao contrário, hoje a histeria parece ter se apropriado da transexualidade para postular sua perene pergunta sobre a verdade do sexo.

\section{Epidemias de histeria}

Aquilo que podemos qualificar hoje como uma verdadeira epidemia de histeria trans no mundo contemporâneo possui antecedentes célebres. Surpreende, contudo, que não haja nenhuma referência às grandes epidemias 


\section{ARTIGOS}

de histeria em importantes obras históricas. ${ }^{17}$ Sigmund Freud, em seu primeiro artigo sobre a histeria, escrito em 1888 para a enciclopédia médica Villaret, recorda a ocorrência dessas epidemias

$\mathrm{Na}$ Idade Média, as neuroses desempenharam um papel significativo na história da civilização; surgiam sob a forma de epidemias, em consequência de contágio psíquico, e estavam na origem do que havia de real na história da possessão pelo demônio e da feitiçaria. (Freud, 1888, p. 79)

Dentre as mais famosas epidemias que ocorreram estão as de $1634 \mathrm{em}$ Loudun, no noroeste da França (cf. Huxley, 1986; Certeau, 1990) e em 1692 em Salem, nos EUA, onde 19 mulheres foram enforcadas, muitas morreram presas e cerca de 200 pessoas foram acusadas de praticar bruxaria e realizar pactos com o demônio. Mas uma epidemia de histeria ocorrida em Morzine, na França, na segunda metade do século XIX, chama atenção por representar à perfeição o deslocamento na cultura da dominância do discurso religioso para o discurso da ciência: ela ficou inscrita nos registros médicos como epidemia "histero-demonopática".

Morzine é uma comuna nos Alpes franceses, na qual durante 16 anos, entre 1857 e 1873, ocorreu uma espantosa epidemia de histeria. Segundo os relatos médicos, tudo começou no dia 14 do mês de março, com a crise de uma menina de dez anos, Perrone Tavernier, que estava naquele momento feliz pela proximidade de sua primeira comunhão. Saindo da igreja determinado dia, viu uma menina ser retirada do rio onde quase se afogara. Embora impressionada e amedrontada, não deixou de ir à aula das freiras, mas poucas horas depois caíu em sua carteira como se estivesse morta, assim permanecendo durante horas. Alguns dias depois, a mesma coisa ocorreu na igreja, e alguns dias mais tarde episódio idêntico ocorreu em sua casa; a partir daí, isso passou a ocorrer de tempos em tempos..$^{18}$

O caso de Perrone é seguido dois meses depois pelo de outra menina, igualmente futura comungante. Os boatos sobre a situação das duas descritas nos relatórios como sendo muito pias e de uma inteligência precoce, louras, com um aspecto franzino, mas no entanto bem comportadas até então

${ }^{17}$ Em especial: H. Ellenberger, Histoire de la découverte de l'inconscient; E. Trillat, História da histeria; I. Veith, Histoire de l'hystérie.

${ }^{18}$ Encontramos tal referência tanto em "A histeria de Morzine" quanto em Le maître et l'hystérique, escritos por G. Wajeman. 
- se espalha rapidamente em narrativas dos fatos, dos gestos e das palavras de ambas. Elas apresentam alucinações de conteúdo místico, que serão responsáveis pela interpretação a ser atribuída a esses fenômenos:

Elas permaneciam imóveis, reviravam os olhos para o céu, depois estendiam os braços para o alto, pareciam receber alguma coisa, faziam movimentos de alguém que abre e lê uma carta: essa pretensa carta lhes causava ora um grande prazer, ora lhes inspirava um profundo desgosto. Depois disso, agiam como se tornassem a dobrar o papel e o devolvessem ao mensageiro invisível que o tinha trazido. Logo após, voltando a si, elas contavam que haviam recebido uma carta da Santa virgem, dizendo-lhes coisas bem amáveis, e que a seu convite tinham estado no Paraíso, o que era muito bonito. Quando a carta desagradava, diziam que tinha vindo do Inferno. (Wajeman, 1976, p. 111)

Tais fenômenos que ninguém podia explicar foram se alastrando a um grande número de crianças, jovens meninas e mulheres.

Havia na história remota de Morzine o relato da presença de feiticeiros que, desde o século XVI, assombravam a localidade e eram responsáveis pela infinidade de pessoas possuídas por demônios que caíam nas malhas dos tribunais da Inquisição. Afirmava-se igualmente que episódios de possessão haviam atingido a comunidade em 1707. Assim, a hipótese inicial sobre os eventos de março de 1857 não poderia ser outra senão a da possessão diabólica. É nesse ambiente receptivo às hipóteses religiosas sobre o mal que o pai de Perrone pergunta se alguém a tocou. Ela responde que uma velha de Gest, uma aldeia vizinha, a tocara no ombro. Depois, afirma que fora Chauplanaz, $\mathrm{o}$ adjunto do prefeito que the passara o mal. Com a designação do feiticeiro, abre-se o campo da possessão e a crença no demoníaco, reatando com a tradição inquisitorial do passado. Agora, proliferam predições das meninas sobre os próximos a serem acometidos do mal. O demônio se apresenta em toda parte:

Umas confessam que ignoram como o mal as tomou; outras asseguram mesmo que enquanto foram bem comportadas, não acreditavam muito na possessão de suas colegas, mas que o mal as obrigou a acreditar. Em geral, todas o atribuem a um olhar, a um toque, a um malefício desse ou daquele indivíduo que elas acusam de feitiçaria. (p. 112)

Mas nada detém o avanço das superstições que proliferam exponencialmente.

Tal como na cena do Fausto de Goethe que antecede o surgimento de Mefistófeles, algumas meninas apresentam crises ao verem um cão preto cruzar seu caminho ou passar diante de suas casas: ele "não era senão 


\section{ARTIGOS}

Chauplanaz metamorfoseado" (p. 113). Certo médico concluiu que era mais difícil afirmar o que não provoca a crise do que o que a desencadeia. Mas ficou estabelecido pelos médicos, em suas pesquisas sobre causas hereditárias, que a viúva Tavernier, mãe de Perrone, de 51 anos de idade, sofria de dores de estômago, espasmos e convulsões desde 1856 - sintomas que serão encontrados depois em cada uma das doentes e especialmente a dor epigástrica, que sempre surge anunciando o mal. Já o cura de Morzine apela para os bons resultados obtidos pelo exorcismo que visa extirpar o demônio do corpo.

Possessão ou doença? Uma batalha de poder foi travada nesse momento entre a religião e a ciência; por isso, quando entra em cena a medicina é para fazer com que seu saber suplante o da religião. O dr. Buet, médico em Morzine, afirmou que se tratava de uma doença, embora paradoxalmente não pudesse incluí-la em qualquer quadro clínico conhecido. O relatório administrativo constatou o aparecimento de uma estranha doença na qual predomina um estado convulsivo acompanhado de fenômenos extraordinários e inexplicáveis. O governo imperial enviou a Morzine como mandatário o dr. Constans, médico inspetor-geral de asilos de alienados. Seu saber forneceu a resposta que subverteu o saber religioso e impôs a vitória da ciência médica pela da inclusão da possessão no discurso médico: tratava-se de um tipo de doença - a histero-demonopatia.

A estrutura de interrogação própria à histeria leva os histéricos os sujeitos de modo geral, pois a estrutura discursiva de base na neurose é a histeria - a se referir ao discurso dominante da época, ao lugar do saber dominante ao qual será dirigida sua interrogação maior — quem sou eu? resposta que será seguida de uma destituição. O que é notável na epidemia de Morzine é o ressurgimento do demônio através do quadro ambíguo da "demonopatia histérica", o qual associa curiosamente religião e ciência. Nas epidemias de histeria da Idade Média, tratava-se de invectivar o saber religioso através das possessões diabólicas que se inscreviam na estrutura discursiva da igreja medieval. Agora, em Morzine, estamos precisamente no momento em que a histeria se desloca do discurso religioso para o discurso médico, ou seja, em que surge a confrontação da histeria com a ciência e a histérica passa do estatuto de possuída ao de doente. Não é um fato anódino que os acontecimentos de Morzine tenham se estendido entre 1857 e 1873 , período que abarca significativamente o intervalo entre a publicação do Traité clinique et thérapeutique de l'hystérie de Paul Briquet, em 1859, e o início das experiências com hipnose de Charcot com as pacientes histéricas na Salpêtrière na década de 1870 . 


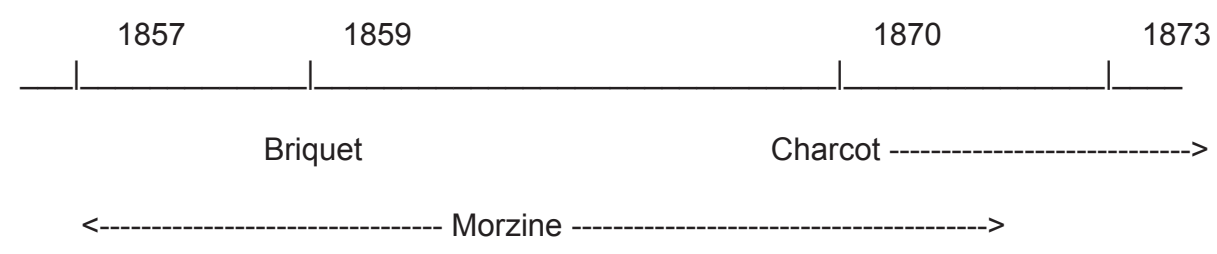

Como sublinha Gérard Wajeman (1976), Morzine se situa justo "entre um primeiro tempo em que a histeria recebe o direito à ciência [Briquet] $\mathrm{e}$ um segundo em que ela será reconhecida como entidade clínica [Charcot]" (p. 37). Outro fato significativo é que não se tem nenhum relato testemunhal de nenhum dos atores dessa epidemia, embora estes tenham constituído algumas centenas. Apenas os documentos médicos restaram, mas foram jogados no subsolo de bibliotecas, onde permaneceram inacessíveis e empoeirados. A partir dos eventos de Morzine, a histeria passou a se dirigir à medicina e à psiquiatria, onde ela se alojou mais uma vez num lugar estranho, no qual teve ao mesmo tempo reconhecido e negado seu estatuto de doente mental.

Com o advento da psicanálise, a histeria adquiriu inicialmente o estatuto 322 de psiconeurose, ao lado das obsessões e fobias, passando em seguida a ser explorada como uma forma excelsa da manifestação subjetiva. A partir do DSM-III, publicado em 1980, a histeria foi retirada dos quadros internacionalmente reconhecidos de classificação nosológica psiquiátrica, ${ }^{19} \mathrm{o}$ que deve ser interpretado como um rechaço profundo das principais teses psicanalíticas que até o momento dominavam a psicopatologia. Os diferentes elementos que compõem os quadros histéricos foram pulverizados em diversos tipos de transtornos, fazendo com que a histeria desaparecesse como quadro clínico. Terá essa exclusão levado a histeria a se dirigir à medicina e à cirurgia com suas demandas de transição e destransição sexual?

\section{A epidemia trans}

A pergunta feita por muitos psicanalistas "onde está a histeria hoje?" pode receber respostas opostas: ela não está em nenhum lugar, caso a procuremos nos manuais contemporâneos de diagnóstico psicopatológico; ela está

${ }^{19}$ Mesma edição em que a categoria do transexualismo aparece pela primeira vez. 


\section{ARTIGOS}

em toda parte, caso a definamos segundo o discurso psicanalítico, que localiza nela a própria estrutura do sujeito.

Estaria a histeria se manifestando hoje em grande parte através das questões ligadas ao gênero e em especial à transexualidade? $\mathrm{O}$ crescimento exponencial de casos na atualidade nos leva a indagar se ela não é a forma contemporânea por excelência da histeria. Ao encontrar na rede de informação e na globalização cultural o vetor de contágio epidêmico e na medicina moderna respostas pragmáticas para as mais diferentes inquietações relativas ao corpo, a transexualidade tem recebido de forma rápida e simplista - tal qual a prescrição de um medicamento — a solução a ser dada aos conflitos do sujeito com seu sexo: "mude-o".

Segundo o portal Brasil, ${ }^{20}$ até 1997, cirurgias de mudança de sexo eram proibidas no país e pessoas que desejassem passar pela mesma eram obrigadas a recorrer a clínicas clandestinas ou, mais frequentemente, a médicos no exterior. Em 2008, seguindo as diretrizes do Conselho Federal de Medicina o governo brasileiro oficializou o "Processo Transexualizador" — que inclui a hormonioterapia e a cirurgia de redesignação sexual — por meio do Sistema Único de Saúde (SUS). A estatística apresentada é a seguinte: até 2014, foram realizados no Brasil 6.724 procedimentos ambulatoriais e 243 procedimentos cirúrgicos em quatro serviços habilitados no SUS. Contudo, os dados apresentados no site do governo representam uma subestatística, pois incluem apenas os atendimentos realizados no serviço público de saúde e não contabilizam a grande demanda de tratamento nas clínicas privadas.

Desde novembro de 2013, o Ministério da Saúde, por meio da Portaria n. 2.803, ampliou o processo transexualizador no SUS, aumentando o número de procedimentos ambulatoriais e hospitalares, incluindo a redesignação sexual de mulher para homem. Pelo caráter irreversível do processo, é necessário que o paciente preencha os seguintes requisitos: maioridade, acompanhamento psicoterápico por pelo menos dois anos, laudo psicológico/psiquiátrico favorável e diagnóstico de transexualidade. Atualmente, o Conselho Federal de Medicina tem discutido a possibilidade de redução da idade mínima para ingresso no processo transexualizador. No Hospital das Clínicas de São Paulo foi criado em 2010 o Ambulatório Transdisciplinar de Identidade de Gênero e Orientação sexual, no qual crianças, adolescentes e seus familiares são acolhidos para tratar de questões relativas ao gênero; o tratamento é iniciado

${ }^{20}$ Recuperado em 01 de maio de 2017. 
com bloqueadores hormonais para retardar a puberdade e aos 16 anos podem iniciar o tratamento feito com uso dos hormônios do sexo oposto.

Será que podemos encontrar na própria estrutura histérica os elementos em jogo para a multiplicação de demandas de mudança de sexo ocorridas em todo o mundo nas últimas décadas? ${ }^{21}$ Estará a sugestionabilidade, que Freud sempre considerou fenômeno universal, na base desse contágio? A sugestionabilidade própria à histeria é absolutamente notável: seja na vida cotidiana, na enorme difusão das ingênuas previsões astrológicas, por exemplo; seja no campo da psicopatologia, quando um sujeito delirante, como Jim Jones, levou em 1978 mais de novecentas pessoas, entre adultos e crianças, ao suicídio coletivo. ${ }^{22}$ Outra grande evidência disso é o fato de que há um pacto silencioso na mídia de evitar veicular notícias sobre suicídios, na medida em que isso pode se propagar na população de forma incontrolável. O que Lacan permitiu elucidar foi que a aptidão contínua da histérica à sugestão é um fato de estrutura: faltoso em seu cerne, o sujeito se fascina por todo significantemestre $\left(\mathrm{S}_{1}\right)$ que the dê a ilusão de poder preencher sua falha, mas ato contínuo denuncia a impotência do saber do mestre para tamponá-la.

O intuito de nosso trabalho é chamar atenção para o fato de que esse 324 elemento essencial - a histeria e suas manifestações polimorfas - deve ser colocado na discussão da transexualidade, sob pena de que ela continue a ser abordada de modo absolutamente ingênuo quanto à estrutura do sujeito, com possíveis graves consequências - dentre elas o suicídio e a irreversibilidade ao estado anterior do corpo, no caso do desejo de destransição quando práticas de transformação corporal irreversíveis são postas em ação como última e única possibilidade. Hoje, a gravidade dessa situação está ainda mais alarmante, uma vez que crianças muito pequenas passaram a receber o diagnóstico de transexualidade não só da medicina como dos próprios pais. A novidade agora é que a mera indagação ou afirmação de uma criança de pertencer ao sexo oposto passa a ser lida por pais e médicos como sinal de transexualidade, ensejando o início precoce de tratamentos hormonais e a previsão futura de cirurgias de transformação corporal. Em nossa sociedade do espetáculo — na qual a imagem tende a sobrepujar qualquer outro valor

\footnotetext{
${ }^{21}$ No livro que está sendo escrito pelos autores deste artigo, serão trazidos dados internacionais pesquisados.

${ }^{22} \mathrm{O}$ caso das irmãs Papin, relatado por Lacan, revela igualmente a ação indutora de uma jovem delirante sobre sua irmã, levando-a a participar de um crime hediondo.
} 


\section{ARTIGOS}

—, e das redes sociais — que disseminam em segundos de uma ponta a outra do planeta as informações mais impactantes - torna-se urgente utilizar todos os recursos possíveis para interrogar de maneira efetiva o lugar assumido pela transexualidade: lugar de valorização avassaladora da imagem do corpo e das incessantes intervenções sobre o real.

\section{Referências}

Amorim, L., \& Jorge, M. A. C. (1982). Transexualismo: a exigência de harmonia. Maisum, Boletim Periódico do Colégio Freudiano do Rio de Janeiro, 13, "10 Mutirão de Psicanálise: A diferença sexual", 1982.

André, S.(1987). O que quer uma mulher? Rio de Janeiro: Jorge Zahar.

Benjamin, H. (1966). The transsexual phenomenon. Nova York: The Julian Press Inc. Publishers.

Bonfanti, L. (1971). The witchcraft Hysteria of 1692 (Vol. 1). New England Historical Series. Wakefield: Pride Publications.

Briquet, P. (1859). Traité clinique et thérapeutique de l'hystérie. Paris: Baillière.

Cauldwell, D. O. (2001, abr.-jun.). Psychopathia transexualis. The International Journal of Transgenderism, 5(2). (Texto publicado originalmente em Sexology, 16, 274-280, 1949). Disponível em https://www.atria.nl/ezines/web/IJT/97-03/ numbers/symposion/cauldwell_02.htm

Certeau, M. de (1990). La possession de Loudun. Paris: Archives Gallimard/Julliard. Chauvelot, D. (2001). Historia de la histeria. Madrid: Alianza Editorial.

Clavreul, J. (1983). A ordem médica. São Paulo: Brasiliense.

Czermak, M. (1991). Paixões do objeto: estudo psicanalítico das psicoses. Porto Alegre: Artes Médicas. (Texto original publicado em 1986).

Czermak, M. (2006, março). O transexualismo: pequena clínica portátil para uso do psiquiatra contemporâneo. Revista Tempo Freudiano, 7, 147-156: “A clínica da psicose: Lacan e a psiquiatria".

Didi-Huberman, G. (2012). Invention de l'hystérie, Paris: Macula.

Ellenberger, H. F. (1994). Histoire de la découverte de l'inconscient. Paris: Fayard.

Ferreira, N. P., \& Motta, M. A. (2014). Histeria: o caso Dora. Rio de Janeiro: Zahar.

Freud, S. (1972a). Fragmentos da análise de um caso de histeria. In Edição Standard Brasileira das Obras Psicológicas Completas de Sigmund Freud (Vol. VII). Rio de Janeiro: Imago. (Trabalho original publicado em 1888).

Freud, S. (1972b). Meus pontos de vista sobre o papel desempenhado pela 


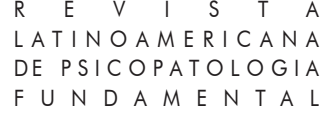

sexualidade na etiologia das neuroses. In Edição Standard Brasileira das Obras Psicológicas Completas de Sigmund Freud (Vol. VII). Rio de Janeiro: Imago. (Trabalho original publicado em 1906[1905]).

Freud, S. (1972c). O tratamento psíquico (ou mental). In: Edição Standard Brasileira das Obras Psicológicas Completas de Sigmund Freud (Vol. VII). Rio de Janeiro: Imago. (Trabalho original publicado em 1905).

Freud, S. (1976). Fantasias histéricas e sua relação com a bissexualidade. In Edição Standard Brasileira das Obras Psicológicas Completas de Sigmund Freud (Vol. IX). Rio de Janeiro: Imago. (Trabalho original publicado em 1908).

Freud, S. (1977). Histeria. In: Edição Standard Brasileira das Obras Psicológicas Completas de Sigmund Freud (Vol. I). Rio de Janeiro: Imago. (Trabalho original publicado em 1888).

Freud, S. (1989). Sobre a gênese do fetichismo. Revista internacional de história da psicanálise, 1 .

Frignet, H. (2002). O transexualismo. Rio de Janeiro: Companhia de Freud.

Grimal, P. (1993). Dicionário da mitologia grega e romana. Rio de Janeiro: Bertrand Brasil.

Huxley, A. (1986). Os demônios de Loudun. São Paulo: Círculo do Livro.

Jorge, M. A. C. (2000). Fundamentos da psicanálise de Freud a Lacan-vol. 1: As bases conceituais. Rio de Janeiro: Jorge Zahar.

Jorge, M. A. C. (2002). Discurso e liame social: apontamentos sobre a teoria lacaniana dos quatro discursos. In D. Rinaldi, \& M. A. C. Jorge (Orgs.), Saber, verdade e gozo - leituras de $\mathrm{O}$ seminário, livro 17 de Jacques Lacan. Rio de Janeiro: Rios Ambiciosos. Mestrado em Pesquisa e Clínica em Psicanálise Instituto de Psicologia - UERJ, 2002.

Jorge, M. A. C. (2010). Fundamentos da psicanálise de Freud a Lacan-vol. 2: A clínica da fantasia. Rio de Janeiro: Jorge Zahar.

Jorge, M. A. C. (2017). Fundamentos da psicanálise de Freud a Lacan-vol. 3: A prática analítica. Rio de Janeiro: Zahar.

Kaz, R. (2017, maio). Retrato de uma menina: ser transgênero aos onze anos de idade. Piauí, 128, 16-23.

Lacan, J. (1998a). Escritos. Rio de Janeiro: Jorge Zahar. (Trabalho original publicado em 1966).

Lacan, J. (1998b). De uma questão preliminar a todo tratamento possível da psicose. In Escritos. Rio de Janeiro: Jorge Zahar. (Trabalho original publicado em 1959).

Lacan, J. (1998c). Subversão do sujeito e dialética do desejo no inconsciente freudiano. In Escritos. Rio de Janeiro: Jorge Zahar. (Trabalho original publicado em 1960)

Rev. Latinoam. Psicopat. $\overline{\text { Fund., São Paulo, }}$ 20(2), 307-330, jun. 2017 


\section{ARTIGOS}

Lacan, J. (1979). O seminário. Livro 11. Os quatro conceitos fundamentais da psicanálise. Rio de Janeiro: Jorge Zahar. (Trabalho original publicado em 1964).

Lacan, J. (1992). O seminário. Livro 17. O avesso da psicanálise. Rio de Janeiro: Jorge Zahar. (Trabalho original publicado em 1969-1970).

Lebrun, J.-P. (1999). Le transsexuel, enfant-modèle de la science. Essaim, 3, 53-68.

Leite, S. (2016). Histeria de conversão, ainda?. In S. Leite, \& T. Costa (Orgs.), Letras do sintoma. Rio de Janeiro: Contra Capa.

Maleval, J.-C. (2009). Locuras histéricas y psicoses dissociativas. Buenos Aires: Paidós.

Maurano, D. (2010). Histeria - o princípio de tudo. Rio de Janeiro: Civilização Brasileira.

Mesmer, F. A. (2006). Mémoire sur la découverte du magnétisme animal. Paris: Allia.

Mieli, P. (2002). Sobre as manipulações irreversíveis do corpo e outros textos psicanalíticos. Rio de Janeiro: Contra Capa/Corpo Freudiano do Rio de Janeiro.

Millot, C. (1989). Nobodaddy: a histeria no século. Rio de Janeiro: Jorge Zahar.

Monseny, J. (1998). L'hystérie, langue de base. In Fondation du Champ Freudien, Le symptôme-charlatan. Paris: Seuil.

Penchansky, M. (2009). Historia universal de la histeria - relatos de amor, pasión y erotismo. Buenos Aires: Grijalbo.

Petros, A. (2013). Las encrucijadas de la sexualidad. Buenos Aires: Psicolibro Ediciones.

Postel, J. (2011). Dictionnaire de la psychiatrie. Paris: Larousse.

Roelens, T., \& Bolaños, T. (1999). Convulsions collectives en terre de haï. Essaim, 3.

Rose, J. (2016, novembro). Quem você pensa que é? Serrote, 24, 108-146.

Safouan, M. (1979a). Contribuição à psicanálise do transexualismo. In Estudos sobre $o$ Édipo. Rio de Janeiro: Zahar.

Safouan, M. (1979b). Da foraclusão. In Estudos sobre o Édipo. Rio de Janeiro: Zahar.

Stoller, R. (1968). Sex \& Gender: the development of masculinity and femininity. London: Karnac books.

Stoller, R. (1982). A experiência transexual. Rio de Janeiro: Imago, 1982. (Trabalho original publicado em 1975).

Travassos, N. P. (2017). A roupa do sexo: transexualidade e psicanálise. Dissertação de Mestrado, Programa de Pós-Graduação em Psicanálise, Universidade do Estado do Rio de Janeiro, março de 2017.

Trillat, É. (1991). História da histeria. São Paulo: Escuta.

Veith, I. (1973). Histoire de l'hystérie. Paris: Seghers. 


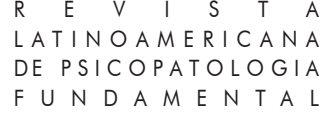

Wajeman, G. (1976). A histeria de Morzine. Lugar, 8, 108-132, “Ornicar? - Bulletin périodique du Champ freudien”. Rio de Janeiro, Editora Rio /Colégio Freudiano do Rio de Janeiro.

Wajeman, G. (1982). Le maître et l'hystérique. Paris: Navarin.

\section{Resumos}

(The transsexual epidemic: Histeria in the era of science and globalization?)

This paper explores issues related to transsexuality based on the psychoanalytic notion of hysteria as the subject basic structure. The impressive hysteria epidemics throughout history reveal how hysteria produces radical questioning of the sexual difference enigma intended to the dominant knowledge of each era. To answer the question about where is the hysteria place nowadays, we launch the following hypothesis: the most significant appearance taken by hysteria today is the transsexual epidemic, produced in the encounter with the science discourse, dominant in the globalized culture.

Key words: Transsexuality, hysteria, epidemic, psychoanalysis, Freud, Lacan

(L' épidémie transsexuelle: l'hysttérie à l'ère de la science et de la mondialisation?)

Cet article porte sur les questions liées à la transsexualité à partir de la notion psychanalytique de l'hystérie comme structure de base du sujet. Les épidémies surprenantes de l'hystérie à travers l'histoire révèlent de quelle façon l'hystérie produit des questions radicales sur l'énigme de la différence sexuelle dirigées au savoir dominant de chaque époque. Pour répondre à la question sur la place de l'hystérie dans la contemporanéité, nous introduisons l'hypothèse suivante : aujourd'hui, la forme la plus importante assumée par l'hystérie est l'épidémie de la transsexualité. Celle-ci se produit dans la rencontre avec le discours de la science, qui est dominant dans la culture mondialisée.

Mots clés: Transsexualité, hystérie, épidémie, psychanalyse, Freud, Lacan

(La epidemia transexual: ¿histeria en la era de la ciencia y de la globalización?)

Este artículo explora cuestiones relacionadas a la transexualidad desde la noción psicoanalítica de la histeria como estructura básica del sujeto. Las impresionantes epidemias de histeria, que ocurrieron a lo largo de la historia, muestran que la histeria produce cuestionamientos radicales sobre el enigma de la diferencia sexual, cuestionamientos dirigidos al saber dominante de cada época. Para responder a la pregunta sobre cuál es el lugar de la histeria en los tiempos 


\section{ARTIGOS}

contemporáneos, proponemos la siguiente hipótesis: la forma más significativa asumida por la histeria, en los días de hoy, es la epidemia de transexualidad, producida en el encuentro con el discurso de la ciencia, discurso dominante en la cultura globalizada.

Palabras clave: Transexualidad, histeria, epidemia, psicoanálisis, Freud, Lacan

(Die transsexuelle Epidemie: Hysterie im Zeitalter der Wissenschaft und der Globalisierung?)

Der vorliegende Artikel beschäftigt sich mit Fragen zur Transsexualität, basierend auf der psychoanalytischen Auffassung der Hysterie als Grundstruktur des Subjekts. Die historisch aufgetretenen und beeindruckenden Epidemien der Hysterie zeigen auf, wie die Hysterie das Wissen der jeweiligen Epochen in Bezug zum Rätsel des sexuellen Unterschieds radikal in Frage stellt. Um die Frage nach dem Platz der Hysterie in der Gegenwart zu beantworten, stellen wir die folgende Hypothese auf: die Hysterie zeigt sich heute am stärksten in der Epidemie der Transsexualität. Diese manifestiert sich in der Begegnung mit dem Diskurs der Wissenschaft, welche in der globalisierten Kultur eine vorherrschende Stellung einnimmt.

Schlüsselwörter: Transsexualität, Hysterie, Epidemie, Psychoanalyse, Freud, Lacan

(性别转化流行病一科学与全球化时代的一种歇斯底里症?)

本文利用心理分析学中有关歇斯底里症 (histeria) 的理论来探讨 性别转化（transexualidade）的问题。歇斯底里症在历史上曾经是流 行病并且横行多时，它使得人们对性和性别之谜产生强烈的疑问，并在 不同时期对性别划分的主流认知产生怀疑。歇斯底里症在当代社会中占 据什么样的地位？要回答这个问题，我们做如下假设：歇斯底里症在当 今最主要的表现形式就是性别转化流行病, 这个病是在人类文化和科学 知识全球化进程中，有关性别的各种话语的交汇碰撞之中产生的。 关键词：性别转化，歇斯底里症，流行病，精神分析，佛洛伊德，拉孔

Citação/Citation: Jorge, M. A.C., \& Travassos, N. P. (2017, junho). A epidemia transexual: histeria na era da ciência e da globalização? Revista Latinoamericana de Psicopatologia Fundamental, 20(2), 307-330. http://dx.doi.org/10.1590/1415-4714.2017v20n2p307.7

Editores do artigo/Editors: Profa. Dra. Ana Maria Rudge, Profa. Dra. Sonia Leite 


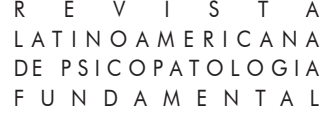

Recebido/Received: 15.5.2017/ 5.15.2017 Aceito/Accepted: 25.5.2017 / 5.25.2017

Copyright: (C) 2009 Associação Universitária de Pesquisa em Psicopatologia Fundamental/ University Association for Research in Fundamental Psychopathology. Este é um artigo de livre acesso, que permite uso irrestrito, distribuição e reprodução em qualquer meio, desde que o autor e a fonte sejam citados / This is an open-access article, which permits unrestricted use, distribution, and reproduction in any medium, provided the original authors and sources are credited.

Financiamento/Funding: Os autores declaram não terem sido financiado ou apoiado / The authors have no support or funding to report.

Conflito de interesses/Conflict of interest: Os autores declaram que não há conflito de interesses / The authors have no conflict of interest to declare.

\section{Marco Antonio Coutinho Jorge}

Psiquiatra; Psicanalista; Professor Associado da Universidade do Estado do Rio de Janeiro - UERJ (Rio de Janeiro, RJ, Br); Membro da Associação Brasileira de Psiquiatria; Membro da Sociedade Internacional de História da Psiquiatria e da Psicanálise; Membro da Associação Insistance (Paris); Diretor do Corpo Freudiano Seção Rio de Janeiro; Autor da série Fundamentos da psicanálise de Freud a Lacan (Zahar) e co-organizador da obra $A s$ homossexualidades na psicanálise na história de sua despatologização (Segmento Farma). Rua Terezina, 19 - Santa Teresa 20240-310 Rio de Janeiro, RJ, Br. macjorge@corpofreudiano.com.br

\section{Natália Pereira Travassos}

Psicanalista; Psicóloga voluntária da ONG Grupo Arco-Íris de Cidadania LGBT (Rio de Janeiro, RJ, Br); Mestre em Clínica e Pesquisa em Psicanálise pelo Programa de Pós-graduação em Psicanálise do Instituto de Psicologia da Universidade do Estado do Rio de Janeiro - UERJ (Rio de Janeiro, RJ, Br).

Rua São Clemente, 262/ 902 - Bloco 2 - Botafogo

22260-000 Rio de Janeiro, RJ, Br

natalia.travassos@gmail.com

\section{(cc) BY-NC}

This is an open-access article, which permits unrestricted use, distribution, and reproduction in any medium for non-commercial purposes provided the original authors and sources are credited. 